\title{
Synoviorthesis with erbium-169: a double-blind controlled comparison of erbium-169 with corticosteroid*
}

\author{
J. M. GUMPEL, S. A. MATTHEWS, AND M. FISHER ${ }^{1}$ \\ From the Rheumatic Diseases Study Group and ${ }^{1}$ Division of Radioisotopes, Northwick Park Hospital, Harrow, \\ Middlesex
}

SUMMARY Intra-articular injections of erbium-169 citrate and methylprednisolone acetate in hand joints were compared in a randomly selected double-blind trial. The patients included 21 with rheumatoid arthritis and 3 with psoriatic arthritis, and the design was an intrapatient comparison. No difference between joints treated with the radioisotope or steroid was observed in the year following injection.

Erbium-169 has been used with considerable success as an intra-articular injection to treat persistent synovitis of the joints of the hand (Menkes et al., 1974). In a double-blind controlled trial (Menkes et al., 1977) joints treated with erbium-169 and $5 \mathrm{mg}$ of prednisolone acetate showed a higher rate of improvement than those treated with saline and prednisolone. This difference was statistically significant. Similar improvement in an open trial was obtained by Ott et al. (1977). We felt there was a need for a further controlled trial, preferably a direct comparison between erbium and steroid.

\section{Patients, materials, and methods}

Patients were selected from the routine rheumatological clinics of 1 physician at Northwick Park and Mount Vernon Hospitals with the exception of 1 outside referral. Criteria for selection included: active joint disease confined to the joint or joints to be treated; synovitis rather than joint destruction; a stable general disease state for 6 months prior to trial; age over 30 and nonpregnant; informed consent to trial.

The study included 24 patients, the sex ratio being 21 females and 3 males. The mean age of the patients was 55 years and the mean duration of disease was $8 \cdot 5$ years. Rheumatoid arthritis was the

*Presented at a meeting of the Heberden Society, Aberdeen 1978.

Accepted for publication 13 September 1978

Correspondence to $\mathrm{Dr}$ J. M. Gumpel, Northwick Park Hospital, Watford Road, Harrow, Middlesex HA1 3UJ. diagnosis in 21 patients, of whom 12 were found to have rheumatoid factor, and psoriatic arthritis in 3. All patients had polyarthritis. The mean number of joints injected per patient was 6 . One joint only was injected in 4 patients. Two patients only had received previous intra-articular corticosteroid injections into these joints.

Erbium-169, a soft beta-emitter (half-life 9.5 days, maximum energy $0.34 \mathrm{Mev}$ ) was obtained as the citrate colloid (Er-MM-1) from CEA, France. The range of its beta emission $(0.3 \mathrm{~mm}$ mean, with a maximum penetration of $1.0 \mathrm{~mm}$ in soft tissue) is very suitable for use in joints with thin synovial membranes close to other structures. It was used in doses of $2 \mathrm{mCi}$ for wrists, $1.0 \mathrm{mCi}$ for metacarpophalangeal joints (MCPs) and 0.5 $\mathrm{mCi}$ for proximal interphalangeal joints (PIPs). The corresponding volumes injected were $1 \cdot 36$, 0.68 , and $0.34 \mathrm{ml}$. These were the minimum volumes possible with the limited concentration on arrival of the material; a smaller volume would have been preferred. The usual dose of methyl prednisolone acetate (as Depomedrone) was $40 \mathrm{mg}$ to wrists, $20 \mathrm{mg}$ to MCPs, and $10 \mathrm{mg}$ to PIP joints. The retention of erbium-169 in treated joints was measured in most patients (J. C. W. Crawley, personal communication).

Assessments were made by the independent assessor (SAM), who remained unaware of the choice of injections throughout. The first was immediately before injection, and was repeated $3,6,12$, and often 24 months afterwards, a fresh proforma being used each time. Each assessment included an index of general disease activity and examination 
Table 1 Joints treated with erbium-169 or methylprednisolone acetate

\begin{tabular}{lll}
\hline & Erbium-169 & Methylprednisolone acetate \\
\hline Wrists & 18 & 12 \\
MCPs & 55 & 44 \\
PIPs & 9 & 9 \\
Total & 82 & 65 \\
\hline
\end{tabular}

of all hand joints. PIPs were measured with a Geigy gauge, MCPs were assessed individually, and wrists measured circumferentially. Each joint was scored for pain and for synovial thickening. The subjective evaluation by the patient was also recorded. Standard photographs and radiographs were taken at 0,6 , and 12 months.

A chart of involved joints to be injected was prepared and the doses made up accordingly. Where symmetrical joints on both hands were to be injected, one of each pair was randomly selected for erbium-169, the other being allocated to corticosteroid. This random selection was performed for each pair of joints, for example, both index MCPs, both middle MCPs, etc. Where unpaired joints were to be treated, a similar process of random selection was undertaken for each joint. After completion this chart was filed separately from the patient's notes for 1 year.

The joints injected are shown in Table 1. All injections were performed in the $x$-ray department under screening control, and a small amount of contrast material was routinely injected to check that the needle tip was in fact intra-articular. In 4 additional joints the injector was unable to enter the joint and the attempt was abandoned. All patients completed a 1 -year review. Only 1 joint was not assessed at 1 year because of a surgical procedure to the wrist involving repair of ruptured tendons.

\section{Results}

There was marked improvement in approximately $25 \%$ of the joints treated (Table 2) irrespective of whether they had been treated with erbium-169 or steroid. The response appeared to be related to the individual patient rather than to the type of injection. The trend was for all joints in a patient either to improve or to show no improvement, and this was maintained from the 3-month assessment to 1 year after injection. No patient identified joints that had improved soon after injection and subsequently deteriorated or others which improved only after an interval.

These subjective findings were confirmed by assessment of synovitis of the treated joints. There was either a marked or complete reduction of syno-
Table 2 Condition of injected joints 1 year after injection

\begin{tabular}{|c|c|c|}
\hline Synovitis & Erbium-169 & Methylprednisolone \\
\hline $\begin{array}{l}\text { Resolution } \\
\text { Marked reduction } \\
\text { Minimal improvement } \\
\text { Unchanged } \\
\text { Total }\end{array}$ & $\begin{array}{l}1(1 \cdot 2 \%) \\
19(23 \%) \\
24(29 \%) \\
38(46 \%) \\
82\end{array}$ & $\begin{array}{l}1(1 \cdot 6 \%) \\
14(22 \%) \\
17(27 \%) \\
32(50 \%) \\
64\end{array}$ \\
\hline
\end{tabular}

vitis in all joints treated or little improvement. No $\overrightarrow{\vec{\omega}}$ different patterns of response were noted for wrists, $\stackrel{\circ}{\circ}$ MCPs, or PIPs. No correlation could be found between the degree of retention of erbium-169 and the clinical response.

In no patient was any acceleration of disease noted, $\dot{\omega}$ nor did any problems follow the injections. The $\nexists$ volume injected occasionally exceeded the apparent음 capacity of the joint, in which case the time takenfor injection was prolonged. Although only cutaneous anaesthesia was used, no patient had undue dis comfort or requested that the procedure be post $-\stackrel{\infty}{\leftrightarrow}$ poned or abandoned.

\section{Discussion}

Our results differ markedly from those obtained in previously published open and controlled trials of intra-articular erbium-169, although the response to steroid was comparable. The rate of improvement of $25 \%$ in this trial should be compared with $54.6 \% \overrightarrow{\text { 을 }}$ in an open trial (Menkes et al., 1974), 58\% in a double-blind controlled trial (Menkes et al., 1977), and $64 \%$ in another open trial (Ott et al., 1977). A major practical difference is that those workers all consider the coincidental injection of corticosteroido to be valuable in preventing an acute irradiation 3 . flare. This would suggest that there is an active synergism between erbium-169 and corticosteroid3 in finger joints. In the knee, our results with yttrium-o 90 without corticosteroid are comparable to those of others using yttrium-90 with corticosteroid.

The general design of this trial was complicated, in that individual joints in a hand were selected foro isotope or steroid rather than hands or patients. 0 Rather more care was necessary in the assessment, N especially in the first, but an intrapatient comparisong is always better than an interpatient comparison Menkes et al. (1977) achieved both, as that controlled trial included a majority of patients receiving either isotope or saline, with an intrapatient comparison 0 of isotope and saline in 27 patients. As comparableo

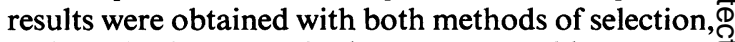
and as the latter method was comparable to ours, $\mathbb{D}$ the design of our trial clearly cannot be a major factor in the differing success rates. 
This work was supported by a grant from the North-west Thames Regional Health Authority. We thank the staff of the Radiology Department for their assistance and patience, and Mrs C. Martin for her co-ordinating role.

\section{References}

Menkes, C. J., Verrier, P., Le Go, A., and Delbarre, F. (1974). Synoviorthèse radio-isotopique des articulations digitales dans le polyarthrite rhumatoide. Annales de Chirurgie, 28, 888-889.

Menkes, C. J., Le Go, A., Verrier, P., Aignan, M., and
Delbarre, F. (1977). Double blind study of erbium-169 injection (synoviorthesis) in rheumatoid digital joints. Annals of the Rheumatic Diseases, 36, 254-256.

Ott, H., Boussina, I., and Fallet, G. H. (1977). La synoviorthèse des articulations digitales de la main à l'erbium 169. Schweizerische Medizinische Wochenschrift, 107, 13661371.

ADDENDUM. Since this report was written a comparisom of erbium-169 versus triamcinolone hexacetonide has been published by A. Ruotsi, M. Hypén, A. Rekonen, and M. Oka (Annals of the Rheumatic Diseases, 1979, 38, 45-47). 